\title{
Characterization of a New Staphylococcus aureus Kayvirus Harboring a Lysin Active against Biofilms
}

\author{
Luís D. R. Melo ${ }^{(\mathbb{D}}$, Ana Brandão, Ergun Akturk, Silvio B. Santos ${ }^{(\mathbb{1})}$ and Joana Azeredo* \\ LIBRO—Laboratório de Investigação em Biofilmes Rosário Oliveira, Centre of Biological Engineering, \\ University of Minho, Campus de Gualtar, 4700-057, Braga, Portugal; lmelo@deb.uminho.pt (L.D.R.M.); \\ anacatarinabr@hotmail.com (A.B.); ergun.akturk@ceb.uminho.pt (E.A.); silviosantos@ceb.uminho.pt (S.B.S.) \\ * Correspondence: jazeredo@deb.uminho.pt; Tel.: +351-253-604-419
}

Received: 26 February 2018; Accepted: 4 April 2018; Published: 7 April 2018

\begin{abstract}
Staphylococcus aureus is one of the most relevant opportunistic pathogens involved in many biofilm-associated diseases, and is a major cause of nosocomial infections, mainly due to the increasing prevalence of multidrug-resistant strains. Consequently, alternative methods to eradicate the pathogen are urgent. It has been previously shown that polyvalent staphylococcal kayviruses and their derived endolysins are excellent candidates for therapy. Here we present the characterization of a new bacteriophage: vB_SauM-LM12 (LM12). LM12 has a broad host range $(>90 \% ; 56$ strains tested), and is active against several MRSA strains. The genome of LM12 is composed of a dsDNA molecule with 143,625 bp, with average GC content of $30.25 \%$ and codes for 227 Coding Sequences (CDSs). Bioinformatics analysis did not identify any gene encoding virulence factors, toxins, or antibiotic resistance determinants. Antibiofilm assays have shown that this phage significantly reduced the number of viable cells (less than one order of magnitude). Moreover, the encoded endolysin also showed activity against biofilms, with a consistent biomass reduction during prolonged periods of treatment (of about one order of magnitude). Interestingly, the endolysin was shown to be much more active against stationary-phase cells and suspended biofilm cells than against intact and scraped biofilms, suggesting that cellular aggregates protected by the biofilm matrix reduced protein activity. Both phage LM12 and its endolysin seem to have a strong antimicrobial effect and broad host range against $S$. aureus, suggesting their potential to treat $S$. aureus biofilm infections.
\end{abstract}

Keywords: Staphylococcus aureus; Kayvirus; bacteriophage; endolysin; biofilms

\section{Introduction}

Currently, the development of bacterial resistance to antibiotics has become a global concern. Very recently, the World Health Organization (WHO) published a list of priority pathogens resistant to antibiotics, encouraging the scientific community and pharmaceutical industries to focus on the development of new antimicrobials to combat antimicrobial-resistant (AMR) pathogens [1]. In the referred report, methicillin-resistant Staphylococcus aureus (MRSA), vancomycin-intermediate S. aureus (VISA), and vancomycin-resistant S. aureus (VRSA) were considered of high importance [1].

Antibiotic-resistant $S$. aureus is well-established in both community and healthcare settings, being one the most frequently isolated pathogens in hospital-associated infections (HAI) [2]. This microorganism is a resourceful pathogen that can cause a wide range of diseases, from food poisoning to life-threatening diseases such as pneumonia, infective endocarditis, or sepsis [3].

Recent evidence has revealed that $S$. aureus infections are one of the main causes of hospital infections, leading to increasing rates of morbidity and mortality, which ultimately increase health care costs $[4,5]$. The severity of $S$. aureus infections is mostly related to its intrinsic ability to acquire and express antibiotic-resistance genes. Presently, S. aureus has acquired a resistance to practically 
all antibiotics [6]. Moreover, its ability to adhere to host tissues and evade human host defenses, namely by the formation of thick biofilms, increases the difficulty in treating this pathogen [7]. Indeed, biofilm cells are described as being more tolerant to antibiotics than planktonic cells, mainly due to the antibiotics' difficulty penetrating the complex biofilm matrix [8]. Moreover, the slow growth of biofilm cells limits therapeutic success, as several antibiotics can only target active cells.

Bacteriophages, also known as phages, are natural bactericidal agents that specifically lyse bacteria. Due to their bacterial host specificity and bacteriolytic activity against antibiotic-resistant strains, the use of phage therapy has been suggested as a valuable approach to control numerous pathogenic bacteria, namely S. aureus. During the last decade, a huge importance has been given to the study of staphylococcal phages, namely their genomes. Although the majority are temperate siphoviruses, staphylococcal myoviruses have been described as very promising for therapy purposes $[9,10]$. Moreover, staphylococcal lytic phages have demonstrated their in-vitro potential as anti-biofilm agents on food matrices and on clinical models, controlling in-vitro biofilms [11-13].

In addition, phage-encoded cell-wall-degrading enzymes, named endolysins, have been proposed to be potent antibacterial agents [14]. These peptidoglycan hydrolases evolved to rapidly break down the bacterial cell wall, thereby allowing the release of phage progeny. When endolysins were expressed heterologously and added to the cells from the outside, they displayed a high bacteriolytic effect in Gram-positive cells.

In this study, we report the isolation of a new Kayvirus phage, named vB_SauM-LM12 (LM12). This phage was characterized morphologically and genomically, revealing suitable properties for therapy. We also purified and characterized the staphylococcal endolysin E-LM12, derived from the phage LM12, and demonstrated the former's efficacy as a valuable anti-biofilm agent.

\section{Materials and Methods}

\subsection{Bacterial Strains and Culture Conditions}

S. aureus collection strains were obtained from American Type Culture Collection (ATCC) and Spanish Type Culture Collection (CECT). Additional S. aureus clinical isolates were obtained from the Hospital Strain Collection (Braga, Portugal). To complete the phage and endolysin lytic spectrum, additional staphylococcal strains, and other Gram-positive species from our collection were used. This accounts to a total of 39 strains used (Table 1), including 29 S. aureus, 7 non-S. aureus staphylococcal strains, and one representative of Enterococcus faecalis, Enterococcus faecium, and Listeria monocytogenes. All strains were grown in Tryptic Soy Broth (TSB, VWR Chemicals, Randor, PA, USA), Tryptic Soy Agar (TSA; VWR Chemicals) or in TSA soft overlays (TSB with $0.6 \%$ agar) at $37^{\circ} \mathrm{C}$.

Table 1. Phage vB_SauM-LM12 (LM12) spectrum of activity with efficiency of plating (EOP) and E-LM12 lytic spectrum. High, moderate, and low efficiency of plating represent $>10 \%, 0.01-9 \%$, and $<0.01 \%$, respectively.

\begin{tabular}{|c|c|c|c|c|c|c|}
\hline Species & Strain & Origin & $\begin{array}{l}\text { Antibiotic } \\
\text { Resistance }\end{array}$ & $\begin{array}{c}\text { Phage } \\
\text { Infectivity }\end{array}$ & EOP & $\begin{array}{c}\text { Endolysin } \\
\text { Activity }\end{array}$ \\
\hline \multirow[t]{13}{*}{ S. aureus } & ATCC 25923 & Clinical Isolate & Unknown & + & High & + \\
\hline & ATCC BAA-976 & Tracheal aspirate & Unknown & + & Medium & - \\
\hline & CECT 239 & Human lesion & Unknown & + & High & + \\
\hline & Sa1 & Expectoration & MRSA & + & Medium & + \\
\hline & $\mathrm{Sa} 2$ & Expectoration & MRSA & + & Low & + \\
\hline & $\mathrm{Sa} 3$ & Expectoration & MRSA & LFW $^{1}$ & $\mathrm{~N} / \mathrm{A}^{2}$ & + \\
\hline & $\mathrm{Sa} 4$ & Pus & MRSA & + & Medium & + \\
\hline & Sa5 & Bronchial aspirate & MRSA & + & High & + \\
\hline & Sa6 & Expectoration & MRSA & LFW & $\mathrm{N} / \mathrm{A}$ & + \\
\hline & $\mathrm{Sa} 7$ & Expectoration & MRSA & + & High & + \\
\hline & Sa8 & Expectoration & MRSA & + & High & + \\
\hline & Sa9 & Urine & MRSA & LFW & $\mathrm{N} / \mathrm{A}$ & + \\
\hline & Sa10 & Skin exudate & MRSA & + & High & + \\
\hline
\end{tabular}


Table 1. Cont.

\begin{tabular}{|c|c|c|c|c|c|c|}
\hline Species & Strain & Origin & $\begin{array}{l}\text { Antibiotic } \\
\text { Resistance }\end{array}$ & $\begin{array}{c}\text { Phage } \\
\text { Infectivity }\end{array}$ & EOP & $\begin{array}{c}\text { Endolysin } \\
\text { Activity }\end{array}$ \\
\hline & Sa11 & Skin exudate & MRSA & + & Medium & + \\
\hline & Sa12 & Urine & MRSA & + & High & + \\
\hline & Sa13 & Skin exudate & MRSA & + & Medium & + \\
\hline & Sa14 & Urine & MRSA & LFW & $\mathrm{N} / \mathrm{A}$ & + \\
\hline & Sa15 & Expectoration & MRSA & + & High & + \\
\hline & Sa16 & Bronchial aspirate & MRSA & + & Medium & + \\
\hline & Sa17 & Nasal exudate & MRSA & + & LFW & + \\
\hline & Sa18 & Expectoration & MRSA & LFW & $\mathrm{N} / \mathrm{A}$ & + \\
\hline & Sa19 & Expectoration & MRSA & + & High & + \\
\hline & Sa20 & Urine & MRSA & + & Medium & + \\
\hline & $\mathrm{Sa} 21$ & Urine & MRSA & + & High & + \\
\hline & $\mathrm{Sa} 22$ & Expectoration & MRSA & + & High & + \\
\hline & $\mathrm{Sa} 23$ & Expectoration & MRSA & + & High & + \\
\hline & $\mathrm{Sa} 24$ & Skin exudate & MRSA & LFW & N/A & + \\
\hline & $\mathrm{Sa} 25$ & Expectoration & MRSA & + & High & + \\
\hline \multirow{3}{*}{ S. epidermidis } & Sa26 & Expectoration & MRSA & LFW & N/A & + \\
\hline & RP62A & Catheter-associated sepsis & Unknown & LFW & $\mathrm{N} / \mathrm{A}$ & - \\
\hline & 9142 & Blood culture & Unknown & + & Low & - \\
\hline S. haemolyticus & SECOM 065A.1 [15] & Healthy Skin & Unknown & - & - & - \\
\hline S. equorum & SECOM060A [15] & Healthy Skin & Unknown & LFW & $\mathrm{N} / \mathrm{A}$ & - \\
\hline S. capitis & SECOM052A [15] & Healthy Skin & Unknown & + & High & - \\
\hline S. warneri & SECOMF16 [15] & Healthy Skin & Unknown & + & Medium & - \\
\hline S. hominis & SECOMM11 [15] & Healthy Skin & Unknown & LFW & $\mathrm{N} / \mathrm{A}$ & - \\
\hline Enterococcus faecalis & CECT 184 & Milk & Unknown & - & - & - \\
\hline Enterococcus faecium & CECT 410 & Unknown & Unknown & - & - & - \\
\hline $\begin{array}{l}\text { Listeria } \\
\text { monocytogenes }\end{array}$ & CECT 5725 & Chicken & Unknown & - & - & - \\
\hline
\end{tabular}

${ }^{1}$ LFW: Lysis from without; ${ }^{2}$ N/A-non available.

\subsection{Phage Isolation}

Phages were isolated from effluent samples of different wastewater treatment plants (WWTP): Paradela (Vila Verde), Frossos (Braga). The sample enrichment method was performed to isolate phages [16]. Briefly, $20 \mathrm{~mL}$ of the effluent were mixed with $20 \mathrm{~mL}$ double-strength TSB and with $50 \mu \mathrm{L}$ of each of the exponentially grown $S$. aureus strains. The resulting suspensions were incubated at $37^{\circ} \mathrm{C}$ and $120 \mathrm{rpm}$ (BIOSAN ES-20/60, Riga, Latvia) over $24 \mathrm{~h}$. Suspensions were further centrifuged (10 min, $\left.10,000 \times g, 4{ }^{\circ} \mathrm{C}\right)$, and the resulting supernatants were filtered through a $0.22-\mu \mathrm{m}$ PES membrane (GE Healthcare, Little Chalfont, UK).

The presence of phages was checked by performing spot assays on bacterial lawns. Plates were further incubated at $37^{\circ} \mathrm{C}$, for $16-18 \mathrm{~h}$, and the presence of inhibition halos assessed. When present, the inhibition halos where submitted to repeated picking, until single-plaque morphology was observed and ten plaques of each isolated phage were measured and characterized.

\subsection{Phage Production}

Phage particles were produced using the double agar layer method as described before [17]. Briefly, $100 \mu \mathrm{L}$ of a phage suspension at $10^{6} \mathrm{PFU} \cdot \mathrm{mL}^{-1}$ was spread on a S. aureus Sa12 lawn, using a paper strip. After $16-18 \mathrm{~h}$ of incubation at $37^{\circ} \mathrm{C}$, full lysis was checked. Plates were agitated at $120 \mathrm{rpm}$ in an orbital shaker (BIOSAN PSU-10i) for $24 \mathrm{~h}$ at $4{ }^{\circ} \mathrm{C}$, with $3 \mathrm{~mL}$ of an SM Buffer (100 mM $\mathrm{NaCl}, 8 \mathrm{mM} \mathrm{MgSO}_{4}, 50 \mathrm{mM}$ Tris $/ \mathrm{HCl}(\mathrm{pH} 7.5)$ ) to resuspend the phage particles. The liquid phase was collected and centrifuged $\left(10 \mathrm{~min}, 10,000 \times g, 4^{\circ} \mathrm{C}\right)$.

Phages were concentrated, as described by Sambrook and Russel [18]. First, the phage lysate was concentrated with $\mathrm{NaCl}(5.84 \% w / v)$ and PEG $8000(10 \% w / v)$, then purified with chloroform $(1: 4 v / v)$. After filtration through a $0.22-\mu \mathrm{m}$ PES membrane, the samples were stored at $4{ }^{\circ} \mathrm{C}$ until further use. 


\subsection{Electron Microscopy}

Phage particles were sedimented by centrifugation $\left(25,000 \times g, 60 \mathrm{~min}, 4^{\circ} \mathrm{C}\right) \mathrm{using}$ a ScanSpeed 1730R centrifuge (Labogene, Lillerød, Denmark). The pellet was further washed in tap water by repeating the centrifugation step. Subsequently, phage suspension was deposited on copper grids with a carbon-coated Formvar carbon film on a 200 square mesh nickel grid, stained with $2 \%$ uranyl acetate ( $\mathrm{pH}$ 4.0) and examined using a Jeol JEM 1400 transmission electron microscope (TEM) (Tokyo, Japan).

\subsection{Lytic Spectra and Efficiency of Plating}

The host range specificity and lysis efficiency of the isolated phage was screened against all strains listed in Table 1. Bacterial lawns were made on TSA plates by adding $100 \mu \mathrm{L}$ of exponential-phase cell cultures of each strain. The bacterial lawns were spotted with $10 \mu \mathrm{L}$ drops of serial 10-fold dilutions of the phage solution. After $16-18 \mathrm{~h}$ incubation at $37^{\circ} \mathrm{C}$, results were observed and scored. The relative efficiency of plating (EOP) was calculated as the ratio between the phage titer $(\mathrm{PFU} / \mathrm{mL})$ obtained in each isolate and the one obtained in the propagating host.

\subsection{DNA Isolation, Genome Sequencing, and in Silico Analysis}

Phage DNA was extracted essentially as described before [17]. Briefly, purified phages were treated with $0.016 \%(v / v)$ L1 buffer $(300 \mathrm{mM} \mathrm{NaCl}, 100 \mathrm{mM}$ Tris/ $\mathrm{HCl}(\mathrm{pH} 7.5), 10 \mathrm{mM}$ EDTA,

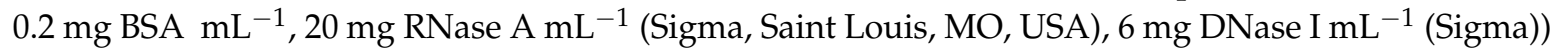
for $2 \mathrm{~h}$ at $37^{\circ} \mathrm{C}$, and the enzymes were further thermally inactivated for $30 \mathrm{~min}$ at $65{ }^{\circ} \mathrm{C}$. Proteins were further digested with $50 \mu \mathrm{g}$ proteinase $\mathrm{K} \mathrm{mL}^{-1}, 20 \mathrm{mM}$ EDTA and $1 \%$ SDS, for $18 \mathrm{~h}$ at $56^{\circ} \mathrm{C}$. This was followed by phenol, phenol:chloroform $(1: 1, v / v)$ and chloroform extractions. DNA was then precipitated with isopropanol and $3 \mathrm{M}$ sodium acetate $(\mathrm{pH} 4.6)$, centrifuged $\left(15 \mathrm{~min}, 7600 \times g, 4^{\circ} \mathrm{C}\right)$, and the pellet air-dried and resuspended in nuclease-free water (Cleaver Scientific, Rugby, UK).

Afterwards, the phage genome was sequenced with an Illumina MiSeq platform conducted in Nucleomics Core (VIB, Leuven, Belgium). LM12 DNA was mixed with another non-homologous phage (at equimolar ratio) and subjected to quality controls using an Agilent Bioanalyzer (Santa Clara, CA, USA). DNA library preparations were made by a custom kit (Nextera XT sample prep, Illumina, San Diego, CA, USA) to generate an average insert size of $500 \mathrm{bp}$. All DNA library preparations were pooled together and sequenced using 150-bp unpaired reads. After processing, reads were trimmed to remove adapters, contaminations, or low-quality sequences. Contigs were assembled, with a relatively homogenous coverage, with the CLC genomics Workbench version 7 (CLC Bio, Aarhus, Denmark), using the de novo assembly algorithm and manual inspection.

The genome was firstly annotated using MyRAST algorithm [19], and was further manually inspected for potential alternative start codons or for the presence of non-annotated CDSs using Geneious 9.1.4 (Biomatters Ltd., Auckland, New Zealand). Functions of the gene products were searched with BLASTp [20] and Pfam [21] programs (E-value $\left.\leq 10^{-5}\right)$. The presence of transmembrane domains was checked using TMHMM [22] and Phobius [18], and membrane proteins were annotated when both tools were in concordance. Protein parameters (molecular weight and isoelectric point) were determined using ExPASy Compute pI/Mw [23]. Transfer RNAs (tRNAs) were scanned using tRNAscan-SE [24] and ARAGORN [18].

Promoter regions were determined using PromoterHunter from the phiSITE database [25] and checked manually. ARNold [26] was used to predict rho-independent terminators and the energy was calculated using Mfold [27]. The DNA homology comparisons between phages were conducted with progressiveMauve [28].

The phylogenetic analysis of homologous phages was performed on Geneious 9.1.4. For phylogenetic purposes, the LM12 genome was aligned with 27 other staphylococcal phage genomes using the MAFFT Alignment on Geneious. The resulting alignment was used to build a phylogenetic tree using a Maximum-Likelihood phylogenetic (PHYML) algorithm with a bootstrapping of 100 . 


\subsection{Expression Plasmid Construction}

Primers containing the restriction cloning sites of NdeI/XhoI (underlined) were designed to amplify the LM12 putative lysin (forward CCGCCG CATATG GAATTCATGGCTAAGACTCAAGC AGAAATAAATAAA, and reverse CCGCCG CTCGAG TTAACCTTTGAATACACCCCAGG) by PCR with Phusion Polymerase (ThermoFisher, Waltham, MA, USA). The PCR product was digested with proper endonucleases (FastDigest-ThermoFisher) and ligated with T4 DNA ligase (New England Biolabs, Ipswich, MA, USA), according to the manufacturer's protocols, into pET28a (Novagen, Merck Millipore, Burlington, MA, USA), resulting in the plasmid pET28a-LM12 encoding the lysin with a C-terminal His-tag. The resulting plasmid was propagated and maintained in E. coli TOP10. The correct insertion of the lysin gene into the plasmid was confirmed by Sanger sequencing (GATC Biotech, Konstanz, Germany).

\subsection{Recombinant Protein Production and Purification}

E. coli BL21(DE3) cells transformed with the recombinant plasmid were grown at $37^{\circ} \mathrm{C}$ in an $\mathrm{LB}$ medium supplemented with the appropriate antibiotic $\left(50 \mu \mathrm{g} / \mathrm{mL}\right.$ of kanamycin), until an $\mathrm{OD}_{620 \mathrm{~nm}}$ of 0.550 and recombinant protein expression was induced by IPTG ( $1 \mathrm{mM}$ final concentration) overnight at $16{ }^{\circ} \mathrm{C}$. The cells were recovered by centrifugation, resuspended in lysis buffer $\left(20 \mathrm{mM} \mathrm{Na} \mathrm{H}_{2} \mathrm{PO}_{4}\right.$, $500 \mathrm{mM}$ sodium chloride, $10 \mathrm{mM}$ imidazole, $\mathrm{pH}$ 7.4), and disrupted to release the expressed protein. Cell disruption was accomplished by three thaw-freezing cycles (from $-80^{\circ} \mathrm{C}$ to room temperature) followed by a 5-min sonication (Cole-Parmer Ultrasonic Processor, Vernon Hills, IL, USA) for 10 cycles (30 s pulse, $30 \mathrm{~s}$ pause) at $40 \%$ amplitude. Soluble cell-free extracts were collected by centrifugation, filtered, and loaded on a $1 \mathrm{~mL}$ Ni-NTA agarose stacked in a Polypropylene column (Qiagen, Hilden, Germany), previously equilibrated with $10 \mathrm{mM}$ imidazole, making use of the protein N-terminal His-tag. The washing step was performed using protein-dependent imidazole concentrations (lysis buffer supplemented with $20 \mathrm{mM}$ imidazole in the first wash and $40 \mathrm{mM}$ imidazole in the second) and elution, carried out with $300 \mathrm{mM}$ imidazole in lysis buffer.

The purified protein was analyzed by SDS-PAGE using a 12\% $(w / v)$ acrylamide gel, followed by BlueSafe staining (NZYTech, Lisbon, Portugal). The eluted protein was concentrated and dialyzed against $20 \mathrm{mM}$ HEPES pH 8.0 using the centrifugal filters Amicon Ultra- $0.5 \mathrm{~mL}$ (Merck Millipore) and stored at $4{ }^{\circ} \mathrm{C}$.

\subsection{Activity on Planktonic Cells}

The activity of E-LM12 lysin against planktonic cells in both exponential and stationary phases was performed as described before [29]. In brief, to obtain a suspension of stationary phase cells, S. aureus was grown for $48 \mathrm{~h}$ at $37^{\circ} \mathrm{C}$ and $120 \mathrm{rpm}$. Cell suspensions were diluted with spent medium (centrifuged medium used to grow the cells, and to avoid regrowth of the cells) to obtain an optical density at $600 \mathrm{~nm}\left(\mathrm{OD}_{600 \mathrm{~nm}}\right)$ of approximately $0.4\left(\sim 5 \times 10^{8}\right.$ colony forming units $\left.(\mathrm{CFU}) \cdot \mathrm{mL}^{-1}\right)$. Exponentially growing cells were obtained by inoculating $10 \mathrm{~mL}$ of fresh TSB with $100 \mu \mathrm{L}$ of the overnight grown culture, and allowing bacteria to grow until $\mathrm{OD}_{600 \mathrm{~nm}}$ reached approximately 0.4 .

Cells were pelleted by centrifugation and further resuspended in $8 \mu \mathrm{M}$ of endolysin. Samples were taken at $2 \mathrm{~h}, 6 \mathrm{~h}$, and $24 \mathrm{~h}$ post-contact with the lysin. The number of cultivable cells $\left(\mathrm{CFU} \cdot \mathrm{mL}^{-1}\right) \mathrm{was}^{-}$ quantified using the microdrop method $(10 \mu \mathrm{L}$ drops of 10 -fold dilutions of the suspension are spotted on agar medium petri plates and the number of CFUs recorded), and the antibacterial activity assessed as the relative inactivation in logarithmic units $\left(\log 10\left(N_{0} / N_{i}\right) ; N_{0}\right.$ is the number of untreated cells in the negative control, and $N_{i}$ is the number of treated cells counted after incubation). Three independent experiments were performed in triplicate. Control experiments were performed by adding $20 \mathrm{mM}$ HEPES, pH 8.0 buffer instead of endolysin suspension. 


\subsection{Biofilm Formation}

Biofilm formation was performed by inoculating one $S$. aureus colony in TSB (10 mL), and incubating for $16 \mathrm{~h}$ in an orbital shaker $(120 \mathrm{rpm}, \mathrm{BIOSAN})$ at $37{ }^{\circ} \mathrm{C}$. To establish mature biofilms, $2 \mu \mathrm{L}$ of the starter culture were transferred into 96-well polystyrene plates (Orange Scientific, Braine-l'Alleud, Belgium) containing $198 \mu \mathrm{L}$ of TSB supplemented with $1 \%$ filtered glucose $(w / v)$ (TSBG). The plates were incubated for $24 \mathrm{~h}$ in an orbital shaker incubator (120 rpm, BIOSAN ES-20/60) at $37^{\circ} \mathrm{C}$. Biofilms were washed twice more with saline solution. After scraping, samples were sonicated for $10 \mathrm{~s}$ at $30 \%$ amplitude to eliminate clusters [30], and the number of cultivable cells determined using the microdrop method. Three independent experiments were performed in triplicate.

\subsection{Biofilm Challenge}

Twenty-four hour biofilms were infected as previously described [29], with some modifications. Briefly, biofilm supernatants were removed, and the biofilms were washed twice with saline solution. Thereafter, $200 \mu \mathrm{L}$ of phage (Multiplicity of infection of 1$)$ or endolysin $(8 \mu \mathrm{M})$ were added to each well. Microplates were incubated at $37^{\circ} \mathrm{C}$ and $120 \mathrm{rpm}$, and samples were taken at $2 \mathrm{~h}, 6 \mathrm{~h}$, and $24 \mathrm{~h}$ post-infection. Samples were sonicated for $10 \mathrm{~s}$ at $30 \%$, and the number of cultivable cells determined using the microdrop method. Three independent experiments were performed in triplicate. Control experiments were performed by adding SM buffer instead of phage suspension, or $20 \mathrm{mM}$ HEPES and pH 8.0 instead of endolysin.

\subsection{Minimal Inhibitory Concentration Assay}

A classical microdilution broth method was used to determine E-LM12 minimal inhibitory concentration (MIC), as previously described [31,32]. All MIC values represent three assays, with three replicates in each assay.

\subsection{Infection of Scraped Biofilm Cells}

To assess lysin activity against disrupted biofilms, $24 \mathrm{~h}$ biofilms were washed twice with saline solution, and the biofilm three-dimensional (3D) structure was disturbed by a slight manual scraping. Biofilm suspension was further challenged with the endolysin, using the conditions described for biofilm challenge. Control experiments were performed by adding HEPES buffer instead of endolysin suspension. Three independent experiments were performed in duplicate.

\subsection{Infection of Suspended Biofilm Cells}

The endolysin activity on biofilm cells was tested by manually scraping double-washed $24 \mathrm{~h}$ biofilms until their full detachment from the surfaces. Samples were homogenized by vortexing, to allow each matrix to detach from the biofilm cells and be further challenged with the endolysin, using reaching the conditions described for the biofilm challenge. Control experiments were performed by adding HEPES buffer instead of endolysin suspension. Three independent experiments were performed in duplicate.

\subsection{Statistical Analysis}

The assays were compared using two-way ANOVA and Sidak post-test, using Prism 6 (GraphPad, La Jolla, CA, USA). Means and standard deviations (SD) were calculated. Differences among conditions were considered statistically significant when $p<0.01$. 


\section{Results}

\subsection{LM12 Is a New S. aureus-Infecting Phage}

Twenty-six MRSA clinical strains were used for phage enrichment, using wastewater treatment plant sewage samples as phage sources. Although no phages were detected in the Frossos effluents, when using Paradela raw sewage a phage vB_SauM_LM12 (LM12) was isolated, and its plaque morphology was characterized by clear and uniform small plaques ( $0.5 \mathrm{~mm}$ in diameter) on the host strain $(n=10)$. According to TEM micrographs, LM12 belongs to the Myoviridae family (Figure 1 ). Phage particles are composed by an icosahedral head, $83 \mathrm{~nm}$ in diameter, and a contractile tail of $168 \times 20 \mathrm{~nm}(n=5)$. Furthermore, phage particles are composed of a neck, conspicuous transverse tail striations, a baseplate, and terminal bulbous spikes.

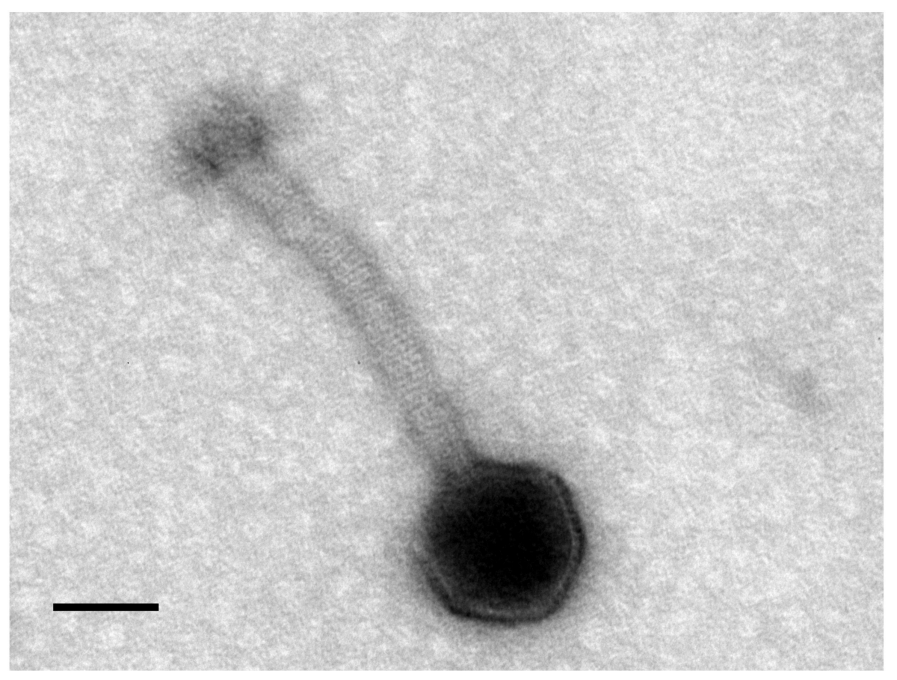

Figure 1. Morphology of LM12. Transmission electron microscopic image of Staphylococcus myovirus LM12 negatively stained with $2 \%(w / v)$ uranyl acetate. Scale bar represents $50 \mathrm{~nm}$.

\subsection{LM12 Is a Polyvalent Phage with a Wide Host Lytic Range among Clinical Isolates}

A collection of 29 S. aureus isolates, seven other staphylococci, and three strains of other Gram-positive pathogens were used to determine the host range of LM12 and corresponding EOP (Table 1). Interestingly, LM12 has a broad spectrum of activity, showing a lytic effect in all S. aureus strains tested, infecting 22 out of the 29 S. aureus strains tested. Moreover, it shows a lytic effect against all other Staphylococcus spp. strains, excluding the S. haemolyticus strain tested. Furthermore, no lysis was observed on non-staphylococcal strains. In some cases, lysis from external events were observed, as phage haloes were observed with high phage concentrations, but no plaques could be seen when decreasing the phage titer. This phenomenon was mainly present on non-S. aureus staphylococcal strains.

Regarding the EOP experiments, in general, LM12 showed high to moderate EOP in the majority of the strains.

\subsection{Antibacterial Assays Show That LM12 Can Inhibit S. aureus Biofilms}

Phage infection was performed on Sa12 24-h biofilms, using a Multiplicity of Infection (MOI) of 1 . According to the infection results, Sa12 can significantly decrease the number of viable biofilm cells about one order of magnitude during the first $6 \mathrm{~h}$ of infection $(p<0.01)$. However, after $24 \mathrm{~h}$, the biofilm cells might have acquired resistance to the phage, and consequently, the numbers of cells after $24 \mathrm{~h}$ of infection increased (Figure S1). 


\subsection{LM12 Genome Is Similar to Kayvirus Genomes}

The complete genomic sequence of bacteriophage LM12 was determined and deposited in GenBank under the accession number MG721208. LM12 has a linear dsDNA genome consisting of 143,652 bp, with a GC content of 29.3\%. Semi-automatic annotation predicted that LM12 encodes 227 proteins, of which 70 have a putative function and 157 are considered hypothetical/novel (Table S1). LM12 genes are packed tightly, occupying 90\% of the genome. Most predicted gene products exhibit homology to known proteins of phages belonging to the Kayvirus genus, mostly to Staphylococcus phages G1, GH15, and P108. Moreover, three tRNA coding for Asp, Phe, and Trp were detected before the lytic module (gp157), and one tRNA coding for Met was detected between two genes with an unknown function ( $g$ p197A and $g p 198$ ).

As in other phages of this genus, long-terminal repeats (LTRs) were detected at the genome ends. Although the exact borders between the LTRs and the rest of phage DNA has not been determined, the region between the bofl and tre $A$ genes was estimated to have $11.5 \mathrm{~Kb}$, which is longer than other kayviruses [10].

The LM12 genome is organized in functional modules, related to DNA replication and transcription, DNA packaging, phage morphogenesis, and cell lysis (Figure 2). On the left arm of LM12 genome are located genes encoding for DNA replication, recombination, and modification, namely nicotinamide phosphoribosyl transferase (gp25) and phosphoribosyl pyrophosphate synthetase (gp27); however, the majority of the genes found encode for proteins with unknown functions.

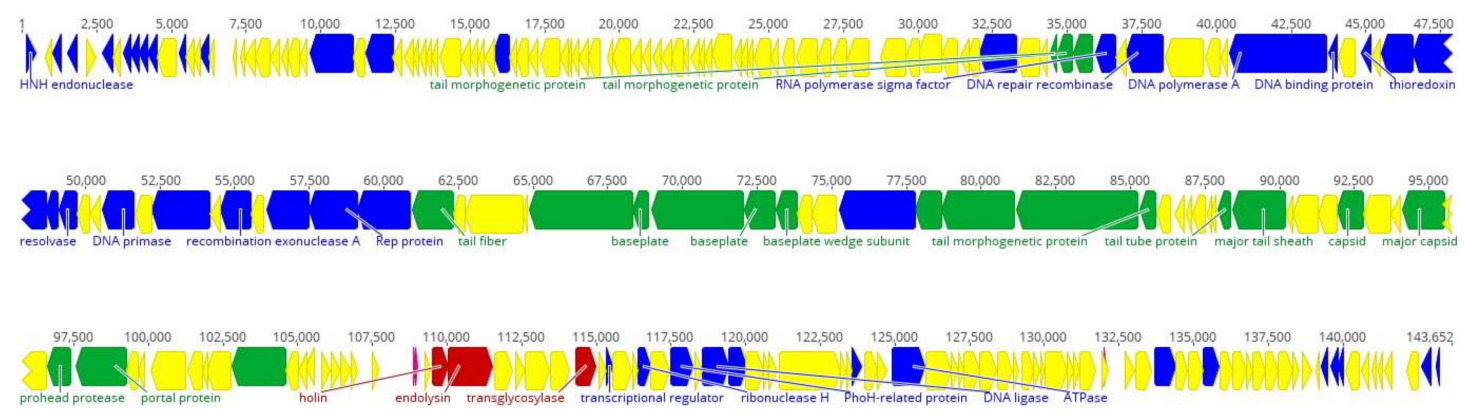

Figure 2. Genome overview of the Staphylococcus phage LM12. Genome map with predicted 227 coding sequences (CDSs) numbered and colored (yellow shows hypothetical proteins, blue shows DNA replication and transcription genes, green represents DNA packaging and phage morphogenesis genes, and red indicates cells lysis genes) according to their predicted function. Some important CDSs are highlighted. Above the genome, the nucleotide position in $\mathrm{kb}$ is given. The figure was performed using Geneious 9.1.4.

In the mid-range of the genome are located the majority of genes encoding for proteins related to DNA replication, recombination, and modification, including DNA polymerase A (gp89), ribonucleotide reductase (gp94 and gp95), DNA repair recombinase (gp85) and DNA primases/ helicases (gp100, gp106, and gp108). Downstream in this region are found some structural genes, namely encoding the baseplate proteins (gp114, gp116, and gp117), tail-related proteins (gp115, gp 121-124, gp131-132), tail fiber proteins (gp109 and gp113), and capsid proteins (gp136 and gp139).

In the beginning of the right arm of the genome, genes encoding DNA packaging proteins, including portal protein (gp142) and terminase (gp149) are found, followed by the lytic module composed of a holin (gp158) and endolysin (gp159). Finally, a small group of DNA replication, recombination, and modification genes, including those encoding the ribonuclease $\mathrm{H}$ (gp169), PhoH-related protein (gp171), nucleoside 2-deoxyribosyltransferase (gp174), and serine/threonine protein phosphatase (gp200).

Moreover, 26 bacterial-origin promoters and 23 rho-independent terminators were detected. Whole-genome comparison analysis has shown that LM12 shares $>90 \%$ identity and $>90 \%$ coverage 
with the majority of the staphylococcal phages belonging to the Kayvirus genus. When the LM12 genome was aligned with 27 other kayviruses, the presence of four groups was visible on the generated tree (Figure 3). The group where phage LM12 was present is composed of three other phages, including IME-SA119 (KR908644), JD007 (NC_019726), and SA5 (JX875065), having 85\%, 82\%, and 83\% identity, respectively. Moreover, LM12 shows identities $<40 \%$ with the other 24 phages analyzed. Progressive Mauve analysis was performed between LM12, IME-SA119, JD007, and SA5 phages, in order to analyze sequence similarities. Results demonstrated that in general, LM12 is homologous with the other three phages, showing few noticeable differences (Figure S2). Several hypothetical proteins (including gp12-14, gp17-18, gp26, gp33, gp43, gp105, gp111, gp145, gp160, and gp198) are encoded within the more divergent genomic regions. Moreover, differences were observed in terminal repeat regions of TreA (gp15) and TreU (gp211). Comparing the four genomes, it was also possible to detect slight differences on the N-terminus of ribonucleotide reductase small subunit (gp94), and on the C-terminus of the tail morphogenetic protein (gp115).

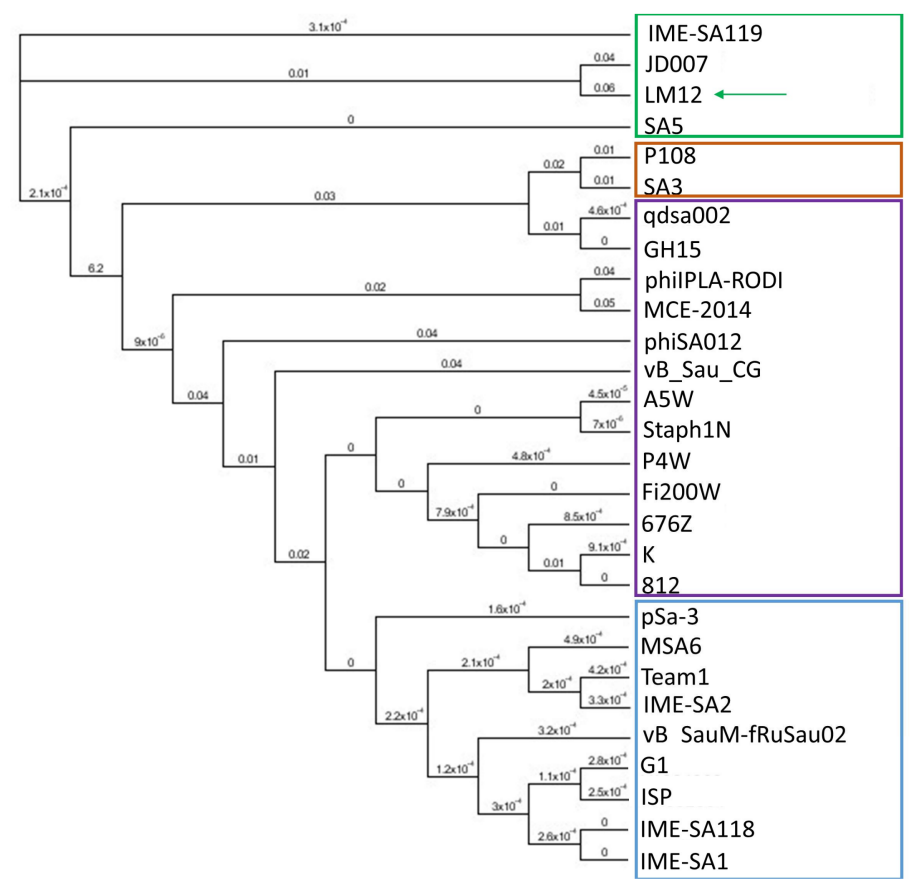

Figure 3. Phylogenetic tree from LM12 genome and its most closely related phage genomes. The tree was generated with a Maximum-Likelihood phylogenetic (PHYML) algorithm, with a bootstrapping of 100. Four groups are indicated (green, orange, purple, and blue), and arrows indicates phage LM12. The figure was performed using Geneious 9.1.4.

\subsection{LM12 Genome Encodes a Modular Lysin with Broad Bactericidal Activity}

In silico analysis of LM12 identified gp159 as the endolysin (E-LM12). This protein has a molecular weight of about 57.74 KDa and a pI of 10.08. This is a 496 amino acid modular protein composed of a N-terminal cysteine, histidine-dependent amidohydrolase/peptidase (CHAP) domain (PF05257), an Amidase-2 (PF01510) domain in the middle, and a SRC Homology 3 (SH3) (PF08460) cell-wall-binding domain on the C-terminus.

BLAST analysis revealed that E-LM12 shows high similarity with the endolysins from several staphylococcal phages, including Staphylococcus phage phiIPLA-RODI (100\% coverage, 98\% identity).

After expression in E. coli, the soluble fraction of E-LM12 was purified by nickel affinity chromatography, via its C-terminal $6 \times$ His-tag. Our procedure led to a purified stock concentration of $120-140 \mathrm{mg} / \mathrm{L}$ of protein in the induced E. coli culture. As expected, E-LM12 was active against a 
wide range of staphylococci strains, including MRSA clinical isolates (Table 1). Moreover, the lysin was unable to lyse other Gram-positive bacteria, such as L. monocytogenes, E. faecium, and E. faecalis.

E-LM12 activity was determined by an MIC assay. The endolysin was able to inhibit $S$. aureus Sa12 growth at concentrations of $34.5 \pm 10.5 \mu \mathrm{g} \cdot \mathrm{mL}^{-1}$.

\subsection{E-LM12 Has an Anti-Biofilm Effect, Being Able to Lyse Exponential and Stationary Phase Cells}

The anti-biofilm potential of the endolysin E-LM12 was assessed (Figure 4a). Two hours after endolysin addition, the number of viable biofilm cells was reduced by about 1.7 orders of magnitude $(p<0.01)$. The reduction decreased slightly after $6 \mathrm{~h}$, when a reduction of about 1.1 orders of magnitude was detected $(p<0.01)$. This reduction was maintained after $24 \mathrm{~h}$ of infection, which suggests that no endolysin resistance was acquired by biofilm cells.

The influence of the biofilm's 3D structure on lysin activity was assessed by scraping the biofilm, in order to disturb its complex 3D structure (Figure $4 b$ ). Results have shown that E-LM12 reduced the number of viable cells by about 1.3 orders of magnitude in all time points tested $(p<0.01)$, suggesting that there are no significant differences on endolysin efficacy against intact or physically disturbed biofilms.

a)

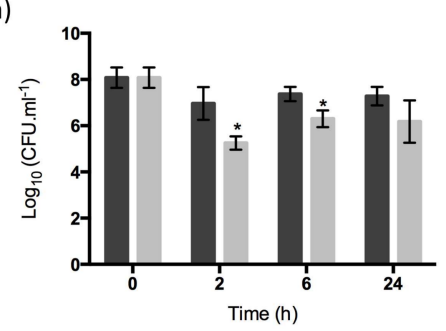

b)

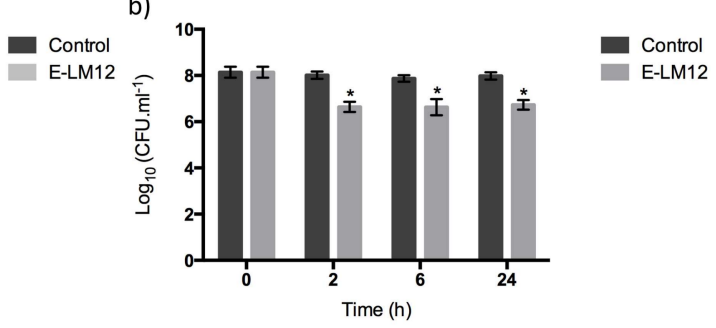

Figure 4. Endolysin E-LM12 activity against S. aureus biofilms, using $8 \mu \mathrm{M}$ (a) intact biofilms; (b) scraped biofilms. Data was assessed by CFU counting, and the values represent the mean (plus or minus) of three independent experiments performed in duplicate. Statistical differences $(p<0.01)$ between the control biofilms and the LM12-treated biofilms $\left.{ }^{*}\right)$ were determined by two-way repeated-measures analysis of variance (ANOVA) with a Sidak post-test.

To get a deeper understanding of endolysin-cell interactions, the protein efficacy was tested against exponential, stationary, and biofilm cells.

E-LM12 demonstrated a high bactericidal activity against exponential-phase cells, reducing the number of viable cells by approximately 4.5 and 4.8 orders of magnitude after $2 \mathrm{~h}$ and $6 \mathrm{~h}$, respectively $(p<0.01)$ (Figure 5a). Moreover, this endolysin was very active against stationary-phase cells, as it was able to reduce the cell numbers by 3.2 orders of magnitude, which was maintained for six hours $(p<0.01)$ (Figure $5 b)$.

To understand the influence of the biofilm matrix in lysin efficacy, biofilms were disrupted and collected into a homogeneous suspension of biofilm cells (Figure 5c). E-LM12 was active against biofilm cells, reducing them by 2.7 orders of magnitude in the first $2 \mathrm{~h}$, which was slightly increased to three orders of magnitude after $6 \mathrm{~h}$ of infection $(p<0.01)$. 

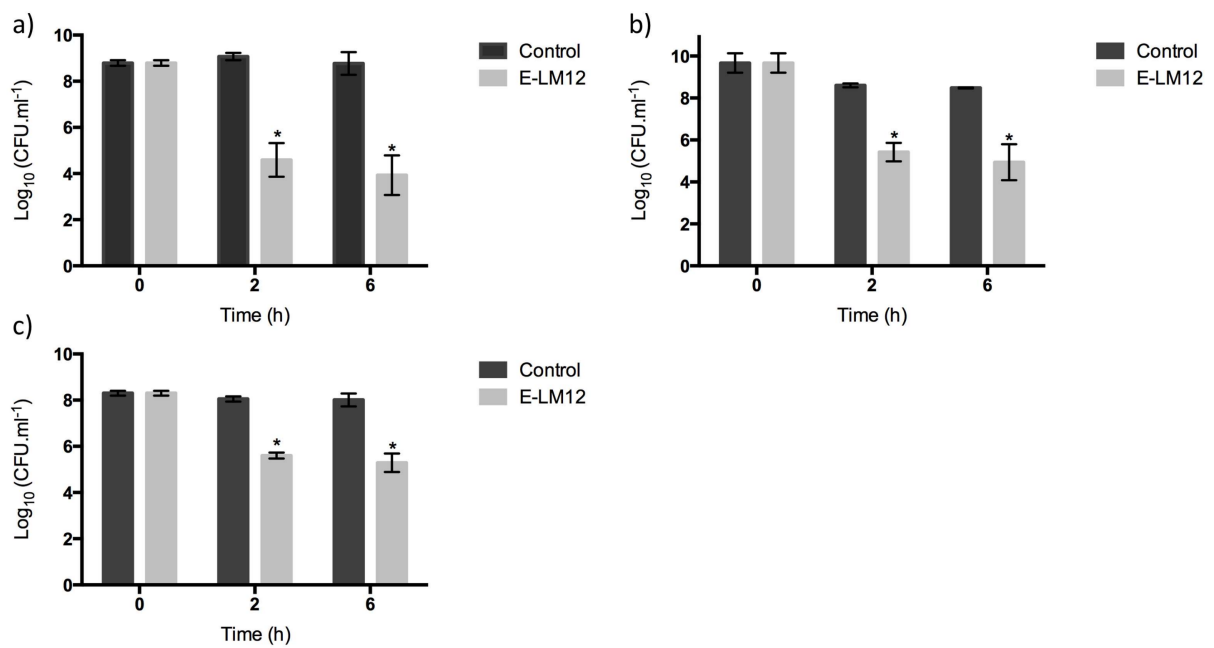

Figure 5. Endolysin E-LM12 activity against $24 \mathrm{~h}$ S. aureus planktonic cells, using $8 \mu \mathrm{M}$ (a) exponential phase cells, (b) stationary phase cells, and (c) biofilm suspended cells. Data was assessed by CFU counting, and the values represent the mean (plus or minus) of three independent experiments performed in duplicate. Statistical differences $(p<0.01)$ between control biofilms and LM12-treated biofilms $\left(^{*}\right)$ were determined by two-way repeated-measures analysis of variance (ANOVA) with a Sidak post-test.

\section{Discussion}

Nowadays, the emergence of multidrug-resistant strains is a main concern [33]. In fact, the WHO recently suggested that the scientific community and pharma industries develop new antimicrobials to combat multi-resistant pathogens, namely the MRSA, VISA, and VRSA strains [1]. The use of lytic bacteriophages and their cell-wall-degrading enzymes (endolysins) have been catching the attention of both researchers and industry as possible tools to combat AMR pathogens. To achieve that, we aimed to isolate phages with lytic activity against $S$. aureus.

As a general strategy, we searched for lytic bacteriophages from environmental sewage waters, using a set of different clinical MRSA isolates to be combined in the sewage enrichment. When Paradela (Vila Verde) effluents were used, it was possible to isolate a $S$. aureus phage. The selected phage was analyzed by TEM, and images suggested that it belongs to the Kayvirus genus [34], formerly known as Twortlikevirus [35]. The phage was named vB_SauM_LM12, according to Kropinski et al.'s [36] recommendations. After sequencing, LM12 was included in the Class III group, as defined by Kwan [37], due to its myovirus morphology, genome size between 140-150 Kbp, and proper gene organization. General genome features-such as $\mathrm{G}+\mathrm{C}$ content, number of genes, tRNA genes, and genome organization - related LM12 with phage K, which is one of the well-studied S. aureus strictly lytic phages [38]. Comparative genomics studies have suggested that LM12 belongs to the Kayvirus genus, clustering with members of the Staphylococcus virus JD7 species. The modular feature of the phage genome is stressed by the presence of $S$. aureus $\sigma 70$ promoters and rho-independent terminators. One particularity of the LM12 genome is the absence of introns, which are very common among Staphylococcus myoviruses [10]. A similar phenomenon was described for Staphylococcus phage GH15, where no introns were detected in its genes for encoding critical enzymatic functions [39]. Recently, Abatangelo et al. [40], suggested that this event might indicate intron loss. Overall, the high genomic similarities and the gene organization suggest genome mosaicism among staphylococcal myoviruses, which is in accordance with the model of modular evolution among phages. In this model, horizontal gene transfer events may lead to new genetic combinations [41].

Usually, Staphylococcus myoviruses are polyvalent phages with strictly virulent behavior, displaying a broad host range. For those reasons, they are considered the most promising phages from a therapeutic point of view [35]. The lytic potential of Kayviruses against S. aureus has been shown in 
different settings [11-13,42]. LM12 was no exception, as it showed a polyvalent behavior lysing all $S$. aureus tested strains, regardless their origin. Usually, viruses of this family adsorb to staphylococcal cells, using the anionic backbone of the cell wall teichoic acid (WTA) as a receptor [43]. More recently, it was shown that myovirus $\Phi S A 012$ possesses at least two receptor binding proteins (RBP), one binding to the $\alpha$-GlcNAc in WTAs and the other expected to bind the WTA backbone [44]. Both $\Phi S A 012$ proteins have homologous proteins in LM12 genome, namely gp109 and gp111. The presence of more than one RBP can justify the broad spectra of Kayviruses.

As more than $60 \%$ of all infections are caused by biofilms [45], the anti-biofilm potential of LM12 was tested. Although several studies focus on biofilm biomass reduction [46,47], the purpose of this study was to assess LM12's direct effect on biofilm cells. During the first $6 \mathrm{~h}$ of infection, $90 \%$ of the biofilm cells were killed. However, a regrowth was observed at $24 \mathrm{~h}$ of infection, which might be related with the emergence of phage-resistant mutants, something already observed when biofilms are challenged by a single phage [48]. Even so, given the broad lytic spectra of LM12 and its quick anti-biofilm potential, the inclusion of LM12 in a cocktail with phages with complementary host ranges could constitute a valuable weapon against AMR Staphylococcus, and prevent the emergence of phage-resistant phenotypes [49].

Besides phages, phage-derived endolysins have been widely studied against S. aureus. Although some endolysins are effective against $S$. aureus biofilms [50-52], few studies are detailed in lysin-biofilm interactions. The endolysin from phage LM12 was cloned, heterologously expressed, and purified. The purified enzyme was named E-LM12, and showed activity against all S. aureus strains tested, namely MRSA clinical isolates. Curiously, no effect was observed against non-S. aureus staphylococci. The amino acid sequence of E-LM12 is very conserved, being closely related to several staphylococcal endolysins [53]. Therefore, it was not surprising that the MIC of E-LM12 was comparable to previous studies with other lysins, namely LysK [30,54]. In addition, it was demonstrated that E-LM12 could disrupt biofilms, causing greater than $90 \%$ reduction of the biofilm cells, at least up to $24 \mathrm{~h}$. In opposition to the phage killing assays, no increase on the biofilm biomass was detected at $24 \mathrm{~h}$ of infection, suggesting that there were no resistance mechanisms developed by the biofilm cells against the endolysins. This absence of resistance to phage's endolysins is in accordance to what has been described [55].

Although the reduction obtained on biofilms was significant, it was considered relevant to understand the influence of the physiological state of the cells with E-LM12 activity, as well as the influence of the complex 3D structure of the biofilm. As biofilms are generally created by bacterial cells that are in a wide range of physiological states, E-LM12 was tested against exponential- and late stationary-phase cells. Although the endolysin E-LM12 has shown to be highly active against both types of cells, higher reductions were observed in exponential-phase cells. S. aureus stationary-phase cells have been shown to have thicker cell walls, with non-uniformly thickened septa, in comparison to exponential-phase cells [56]. Furthermore, the fact that around 12\% of the stems in the peptidoglycan do not have pentaglycine bridges attached [56] might justify the lower activity of the studied endolysin on stationary-phase cells, as the CHAP domain cleaves interpeptide bridges exclusively [57], and the SH3 binding domain recognizes pentaglycine cross bridges in the peptidoglycan [58]. The fact that E-LM12 could infect biofilm cells within the same orders of magnitude as stationary-phase cells suggested that lysin efficacy was not highly affected by cell physiology. A similar phenomenon was detected in the artificially-modified lysin, Art-240, against streptococci [59].

The biofilm matrix can act as a barrier, per se, conferring protection to the biofilm cells-for example, against antibiotics [8]. As the studied endolysin was active against cells with different morphological/physiological states, E-LM12 was tested against biofilms whose architecture was mechanically disrupted (scraped biofilms). Surprisingly, the endolysin activity was not improved by this light disruption, suggesting that the reminiscent cellular aggregates are still protected by the biofilm matrix, and that this matrix interferes with LM12 activity. 
Taken together, phage LM12 and its endolysin seem to have a strong and broad host range effect against $S$. aureus. Their anti-biofilm potential could be increased by using a combination of different phages and endolysins [60], or by using them in combination with matrix-disrupting chemicals [61]. In conclusion, phage LM12, and mainly its endolysin E-LM12, present strong potential in the development of new products to control the highly pathogenic and antibiotic-resistant Staphylococcus aureus.

Supplementary Materials: The following are available online at http:/ /www.mdpi.com/1999-4915/10/4/182/s1, Table S1: Features of LM12 predicted coding sequences (CDSs). For each CDS, the transcription start and stop position and the coding strand is given. At protein level, the corresponding gene product size, molecular weight, and pI, as well as the homolog predicted function, homologs, and E-values and motifs are shown; Figure S1: Phage LM12 infection on $24 \mathrm{~h} \mathrm{~S}$. aureus biofilms, using a multiplicity of infection (MOI) 1 . Data was assessed by colony forming units (CFU) counting, and the values represent the mean (plus or minus) of three independent experiments performed in duplicate. Statistical differences $(p<0.01)$ between control biofilms and LM12-treated biofilms $\left(^{*}\right)$ were determined by two-way repeated-measures analysis of variance (ANOVA) with a Sidak post-test; Figure S2: Multiple genome alignment of Staphylococcus phage LM12 with closest homologs. The figure was performed using Geneious 9.1.4.

Acknowledgments: This study was supported by Lisando $\mathrm{GmbH}$ and by the Portuguese Foundation for Science and Technology (FCT), under the scope of the scope of the project the Project PTDC/BBB-BSS/6471/2014 (POCI-01-0145-FEDER-016678), the strategic funding of UID/BIO/04469/2013 unit, COMPETE 2020 (POCI-01-0145-FEDER-006684), and BioTecNorte operation (NORTE-01-0145-FEDER-000004), funded by the European Regional Development Fund under the scope of Norte2020—Programa Operacional Regional do Norte. Ana Brandão and Ergun Akturk acknowledge FCT for grants SFRH/BD/133193/2017 and PD/BD/13524/2017, respectively. The authors declare that they have no competing financial interests.

Author Contributions: Joana Azeredo and Luís D. R. Melo conceived and designed the experiments; Luís D. R. Melo, Ana Brandão, Ergun Akturk, and Silvio B. Santos performed the experiments; Luís D. R. Melo, Silvio B. Santos, and Joana Azeredo analyzed the data; Luís D. R. Melo wrote the paper. All authors read and approved the final manuscript.

Conflicts of Interest: The authors declare no conflict of interest.

\section{References}

1. World Health Organization. WHO Publishes List of Bacteria for Which New Antibiotics Are Urgently Needed; WHO: Geneva, Switzerland, 2017.

2. Rasmussen, G.; Monecke, S.; Brus, O.; Ehricht, R.; Soderquist, B. Long term molecular epidemiology of methicillin-susceptible Staphylococcus aureus bacteremia isolates in sweden. PLoS ONE 2014, 9, e114276. [CrossRef] [PubMed]

3. Bergin, S.P.; Holland, T.L.; Fowler, V.G., Jr.; Tong, S.Y. Bacteremia, sepsis, and infective endocarditis associated with Staphylococcus aureus. In Current Topics in Microbiology and Immunology; Springer: Berlin, Germany, 2015.

4. Lowy, F.D. Staphylococcus aureus infections. N. Engl. J. Med. 1998, 339, 520-532. [CrossRef] [PubMed]

5. Salge, T.O.; Vera, A.; Antons, D.; Cimiotti, J.P. Fighting mrsa infections in hospital care: How organizational factors matter. Health Serv. Res. 2017, 52, 959-983. [CrossRef] [PubMed]

6. Lowy, F.D. Antimicrobial resistance: The example of Staphylococcus aureus. J. Clin. Investig. 2003, 111, $1265-1273$. [CrossRef] [PubMed]

7. Otto, M. Staphylococcal biofilms. In Current Topics in Microbiology and Immunology; Springer: Berlin, Germany, 2008; Volume 322, pp. 207-228.

8. Flemming, H.C.; Wingender, J. The biofilm matrix. Nature Rev. Microbiol. 2010, 8, 623-633. [CrossRef] [PubMed]

9. Deghorain, M.; van Melderen, L. The Staphylococci phages family: An overview. Viruses 2012, 4, 3316-3335. [CrossRef] [PubMed]

10. Lobocka, M.; Hejnowicz, M.S.; Dabrowski, K.; Gozdek, A.; Kosakowski, J.; Witkowska, M.; Ulatowska, M.I.; Weber-Dabrowska, B.; Kwiatek, M.; Parasion, S.; et al. Genomics of staphylococcal Twort-like phages-Potential therapeutics of the post-antibiotic era. Adv. Virus Res. 2012, 83, 143-216. [PubMed]

11. El Haddad, L.; Roy, J.P.; Khalil, G.E.; St-Gelais, D.; Champagne, C.P.; Labrie, S.; Moineau, S. Efficacy of two Staphylococcus aureus phage cocktails in cheese production. Int. J. Food Microbiol. 2016, 217, 7-13. [CrossRef] [PubMed] 
12. Kelly, D.; McAuliffe, O.; Ross, R.P.; O'Mahony, J.; Coffey, A. Development of a broad-host-range phage cocktail for biocontrol. Bioeng. Bugs 2011, 2, 31-37. [CrossRef] [PubMed]

13. Seth, A.K.; Geringer, M.R.; Nguyen, K.T.; Agnew, S.P.; Dumanian, Z.; Galiano, R.D.; Leung, K.P.; Mustoe, T.A.; Hong, S.J. Bacteriophage therapy for Staphylococcus aureus biofilm-infected wounds: A new approach to chronic wound care. Plast. Reconstr. Surg. 2013, 131, 225-234. [CrossRef] [PubMed]

14. Schuch, R.; Nelson, D.; Fischetti, V.A. A bacteriolytic agent that detects and kills Bacillus anthracis. Nature 2002, 418, 884-889. [CrossRef] [PubMed]

15. Oliveira, F.; Lima, C.A.; Bras, S.; Franca, A.; Cerca, N. Evidence for inter- and intraspecies biofilm formation variability among a small group of coagulase-negative staphylococci. FEMS Microbiol. Lett. 2015, 362. [CrossRef] [PubMed]

16. Melo, L.D.; Sillankorva, S.; Ackermann, H.W.; Kropinski, A.M.; Azeredo, J.; Cerca, N. Characterization of Staphylococcus epidermidis phage vb_seps_sep9-A unique member of the siphoviridae family. Res. Microbiol. 2014, 165, 679-685. [CrossRef] [PubMed]

17. Melo, L.D.; Sillankorva, S.; Ackermann, H.W.; Kropinski, A.M.; Azeredo, J.; Cerca, N. Isolation and characterization of a new Staphylococcus epidermidis broad-spectrum bacteriophage. J. Gen. Virol. 2014, 95, 506-515. [CrossRef] [PubMed]

18. Sambrook, J.; Russell, D.W. Molecular Cloning: A Laboratory Manual, 3rd ed.; Cold Spring Harbor Laboratory Press: New York, NY, USA, 2001.

19. Aziz, R.K.; Bartels, D.; Best, A.A.; DeJongh, M.; Disz, T.; Edwards, R.A.; Formsma, K.; Gerdes, S.; Glass, E.M.; Kubal, M.; et al. The rast server: Rapid annotations using subsystems technology. BMC Genom. 2008, 9, 75. [CrossRef] [PubMed]

20. Altschul, S.F.; Gish, W.; Miller, W.; Myers, E.W.; Lipman, D.J. Basic local alignment search tool. J. Mol. Biol. 1990, 215, 403-410. [CrossRef]

21. Finn, R.D.; Bateman, A.; Clements, J.; Coggill, P.; Eberhardt, R.Y.; Eddy, S.R.; Heger, A.; Hetherington, K.; Holm, L.; Mistry, J.; et al. Pfam: The protein families database. Nucleic Acids Res. 2014, 42, D222-D230. [CrossRef] [PubMed]

22. Kall, L.; Sonnhammer, E.L. Reliability of transmembrane predictions in whole-genome data. FEBS Lett. 2002, 532, 415-418. [CrossRef]

23. Wilkins, M.R.; Gasteiger, E.; Bairoch, A.; Sanchez, J.C.; Williams, K.L.; Appel, R.D.; Hochstrasser, D.F. Protein identification and analysis tools in the expasy server. Methods Mol. Biol. 1999, 112, 531-552. [PubMed]

24. Schattner, P.; Brooks, A.N.; Lowe, T.M. The trnascan-se, snoscan and snogps web servers for the detection of trnas and snornas. Nucleic Acids Res. 2005, 33, W686-W689. [CrossRef] [PubMed]

25. Klucar, L.; Stano, M.; Hajduk, M. Phisite: Database of gene regulation in bacteriophages. Nucleic Acids Res. 2010, 38, D366-D370. [CrossRef] [PubMed]

26. Naville, M.; Ghuillot-Gaudeffroy, A.; Marchais, A.; Gautheret, D. Arnold: A web tool for the prediction of rho-independent transcription terminators. RNA Biol. 2011, 8, 11-13. [CrossRef] [PubMed]

27. Zuker, M. Mfold web server for nucleic acid folding and hybridization prediction. Nucleic Acids Res. 2003, 31, 3406-3415. [CrossRef] [PubMed]

28. Darling, A.E.; Mau, B.; Perna, N.T. Progressivemauve: Multiple genome alignment with gene gain, loss and rearrangement. PLoS ONE 2010, 5, e11147. [CrossRef] [PubMed]

29. Pires, D.; Sillankorva, S.; Faustino, A.; Azeredo, J. Use of newly isolated phages for control of Pseudomonas aeruginosa PAO1 and ATCC 10145 biofilms. Res. Microbiol. 2011, 162, 798-806. [CrossRef] [PubMed]

30. Freitas, A.I.; Vasconcelos, C.; Vilanova, M.; Cerca, N. Optimization of an automatic counting system for the quantification of Staphylococcus epidermidis cells in biofilms. J. Basic Microbiol. 2014, 54, 750-757. [CrossRef] [PubMed]

31. Becker, S.C.; Dong, S.; Baker, J.R.; Foster-Frey, J.; Pritchard, D.G.; Donovan, D.M. Lysk chap endopeptidase domain is required for lysis of live staphylococcal cells. FEMS Microbiol. Lett. 2009, 294, 52-60. [CrossRef] [PubMed]

32. Jones, R.N.; Barry, A.L.; Gavan, T.L.; Washington, J.A.I. Susceptibility tests: Microdilution and macrodilution broth procedures. In Manual of Clinical Microbiology; Balows, A., Hausler, J.W.J., Shadomy, H., Eds.; American Society for Microbiology: Washington, DC, USA, 1985; pp. 972-977. 
33. Spellberg, B.; Guidos, R.; Gilbert, D.; Bradley, J.; Boucher, H.W.; Scheld, W.M.; Bartlett, J.G.; Edwards, J., Jr. Infectious Diseases Society of, A. The epidemic of antibiotic-resistant infections: A call to action for the medical community from the infectious diseases society of America. Clin. Infect. Dis. 2008, 46, 155-164. [CrossRef] [PubMed]

34. Lobocka, M.; Ackermann, H.W.; Kropinski, A.M.; Kuhn, J.K.; Adriaenssens, E.M. To Create One (1) New Genus, Kayvirus, Including Six (6) Newspecies within the Family Myoviridae. ICTV [International Committee for Taxonomy of Viruses] Proposal (Taxoprop) No. 2015.005a-gB. May 2015.

35. Klumpp, J.; Lavigne, R.; Loessner, M.J.; Ackermann, H.W. The Spo1-related bacteriophages. Arch. Virol. 2010, 155, 1547-1561. [CrossRef] [PubMed]

36. Kropinski, A.M.; Prangishvili, D.; Lavigne, R. Position paper: The creation of a rational scheme for the nomenclature of viruses of bacteria and archaea. Environ. Microbiol. 2009, 11, 2775-2777. [CrossRef] [PubMed]

37. Kwan, T.; Liu, J.; DuBow, M.; Gros, P.; Pelletier, J. The complete genomes and proteomes of 27 Staphylococcus aureus bacteriophages. Proc. Natl. Acad. Sci. USA 2005, 102, 5174-5179. [CrossRef] [PubMed]

38. Gill, J.J. Revised genome sequence of Staphylococcus aureus bacteriophage K. Genome Announc. 2014, 2, e01173-13. [CrossRef] [PubMed]

39. Gu, J.; Liu, X.; Lu, R.; Li, Y.; Song, J.; Lei, L.; Sun, C.; Feng, X.; Du, C.; Yu, H.; et al. Complete genome sequence of Staphylococcus aureus bacteriophage GH15. J. Virol. 2012, 86, 8914-8915. [CrossRef] [PubMed]

40. Abatangelo, V.; Peressutti Bacci, N.; Boncompain, C.A.; Amadio, A.F.; Carrasco, S.; Suarez, C.A.; Morbidoni, H.R. Broad-range lytic bacteriophages that kill Staphylococcus aureus local field strains. PLoS ONE 2017, 12, e0181671. [CrossRef] [PubMed]

41. Thomson, N.; Baker, S.; Pickard, D.; Fookes, M.; Anjum, M.; Hamlin, N.; Wain, J.; House, D.; Bhutta, Z.; Chan, K.; et al. The role of prophage-like elements in the diversity of Salmonella enterica serovars. J. Mol. Biol. 2004, 339, 279-300. [CrossRef] [PubMed]

42. Vandersteegen, K.; Mattheus, W.; Ceyssens, P.J.; Bilocq, F.; De Vos, D.; Pirnay, J.P.; Noben, J.P.; Merabishvili, M.; Lipinska, U.; Hermans, K.; et al. Microbiological and molecular assessment of bacteriophage ISP for the control of Staphylococcus aureus. PLoS ONE 2011, 6, e24418. [CrossRef] [PubMed]

43. Xia, G.; Corrigan, R.M.; Winstel, V.; Goerke, C.; Grundling, A.; Peschel, A. Wall teichoic acid-dependent adsorption of staphylococcal siphovirus and myovirus. J. Bacteriol. 2011, 193, 4006-4009. [CrossRef] [PubMed]

44. Takeuchi, I.; Osada, K.; Azam, A.H.; Asakawa, H.; Miyanaga, K.; Tanji, Y. The presence of two receptor-binding proteins contributes to the wide host range of staphylococcal Twort-like phages. Appl. Environ. Microbiol. 2016, 82, 5763-5774. [CrossRef] [PubMed]

45. James, G.A.; Swogger, E.; Wolcott, R.; Pulcini, E.; Secor, P.; Sestrich, J.; Costerton, J.W.; Stewart, P.S. Biofilms in chronic wounds. Wound Repair Regen. 2008, 16, 37-44. [CrossRef] [PubMed]

46. Alves, D.R.; Gaudion, A.; Bean, J.E.; Perez Esteban, P.; Arnot, T.C.; Harper, D.R.; Kot, W.; Hansen, L.H.; Enright, M.C.; Jenkins, A.T. Combined use of bacteriophage $\mathrm{K}$ and a novel bacteriophage to reduce Staphylococcus aureus biofilm formation. Appl. Environ. Microbiol. 2014, 80, 6694-6703. [CrossRef] [PubMed]

47. Vandersteegen, K.; Kropinski, A.M.; Nash, J.H.; Noben, J.P.; Hermans, K.; Lavigne, R. Romulus and remus, two phage isolates representing a distinct clade within the Twortlikevirus genus, display suitable properties for phage therapy applications. J. Virol. 2013, 87, 3237-3247. [CrossRef] [PubMed]

48. Drilling, A.; Morales, S.; Jardeleza, C.; Vreugde, S.; Speck, P.; Wormald, P.J. Bacteriophage reduces biofilm of Staphylococcus aureus ex vivo isolates from chronic rhinosinusitis patients. Am. J. Rhinol. Allergy 2014, 28, 3-11. [CrossRef] [PubMed]

49. Gu, J.; Liu, X.; Li, Y.; Han, W.; Lei, L.; Yang, Y.; Zhao, H.; Gao, Y.; Song, J.; Lu, R.; et al. A method for generation phage cocktail with great therapeutic potential. PLoS ONE 2012, 7, e31698. [CrossRef] [PubMed]

50. Gutierrez, D.; Fernandez, L.; Martinez, B.; Ruas-Madiedo, P.; Garcia, P.; Rodriguez, A. Real-time assessment of Staphylococcus aureus biofilm disruption by phage-derived proteins. Front. Microbiol. 2017, 8, 1632. [CrossRef] [PubMed]

51. Schmelcher, M.; Shen, Y.; Nelson, D.C.; Eugster, M.R.; Eichenseher, F.; Hanke, D.C.; Loessner, M.J.; Dong, S.; Pritchard, D.G.; Lee, J.C.; et al. Evolutionarily distinct bacteriophage endolysins featuring conserved peptidoglycan cleavage sites protect mice from MRSA infection. J. Antimicrob. Chemother. 2015, 70, 1453-1465. [CrossRef] [PubMed] 
52. Son, J.S.; Lee, S.J.; Jun, S.Y.; Yoon, S.J.; Kang, S.H.; Paik, H.R.; Kang, J.O.; Choi, Y.J. Antibacterial and biofilm removal activity of a podoviridae Staphylococcus aureus bacteriophage SAP-2 and a derived recombinant cell-wall-degrading enzyme. Appl. Microbiol. Biotechnol. 2010, 86, 1439-1449. [CrossRef] [PubMed]

53. Haddad Kashani, H.; Schmelcher, M.; Sabzalipoor, H.; Seyed Hosseini, E.; Moniri, R. Recombinant endolysins as potential therapeutics against antibiotic-resistant Staphylococcus aureus: Current status of research and novel delivery strategies. Clin. Microbiol. Rev. 2018, 31, e00071-17. [CrossRef] [PubMed]

54. Mao, J.; Schmelcher, M.; Harty, W.J.; Foster-Frey, J.; Donovan, D.M. Chimeric Ply187 endolysin kills Staphylococcus aureus more effectively than the parental enzyme. FEMS Microbiol. Lett. 2013, 342, 30-36. [CrossRef] [PubMed]

55. Schmelcher, M.; Donovan, D.M.; Loessner, M.J. Bacteriophage endolysins as novel antimicrobials. Future Microbiol. 2012, 7, 1147-1171. [CrossRef] [PubMed]

56. Zhou, X.; Cegelski, L. Nutrient-dependent structural changes in S. aureus peptidoglycan revealed by solid-state NMR spectroscopy. Biochemistry 2012, 51, 8143-8153. [CrossRef] [PubMed]

57. Oliveira, H.; Melo, L.D.; Santos, S.B.; Nobrega, F.L.; Ferreira, E.C.; Cerca, N.; Azeredo, J.; Kluskens, L.D. Molecular aspects and comparative genomics of bacteriophage endolysins. J.Virol. 2013, 87, 4558-4570. [CrossRef] [PubMed]

58. Lu, J.Z.; Fujiwara, T.; Komatsuzawa, H.; Sugai, M.; Sakon, J. Cell wall-targeting domain of glycylglycine endopeptidase distinguishes among peptidoglycan cross-bridges. J. Biol. Chem. 2006, 281, 549-558. [CrossRef] [PubMed]

59. Rodriguez-Rubio, L.; Chang, W.L.; Gutierrez, D.; Lavigne, R.; Martinez, B.; Rodriguez, A.; Govers, S.K.; Aertsen, A.; Hirl, C.; Biebl, M.; et al. 'Artilysation' of endolysin $\lambda$ Sa2lys strongly improves its enzymatic and antibacterial activity against streptococci. Sci. Rep. 2016, 6, 35382. [CrossRef] [PubMed]

60. Hermoso, J.A.; Garcia, J.L.; Garcia, P. Taking aim on bacterial pathogens: From phage therapy to enzybiotics. Curr. Opin. Microbiol. 2007, 10, 461-472. [CrossRef] [PubMed]

61. Abdulamir, A.S.; Jassim, S.A.; Hafidh, R.R.; Bakar, F.A. The potential of bacteriophage cocktail in eliminating Methicillin-resistant Staphylococcus aureus biofilms in terms of different extracellular matrices expressed by PIA, ciaA-D and FnBPA genes. Ann. Clin. Microbiol. Antimicrob. 2015, 14, 49. [CrossRef] [PubMed]

(C) 2018 by the authors. Licensee MDPI, Basel, Switzerland. This article is an open access article distributed under the terms and conditions of the Creative Commons Attribution (CC BY) license (http:/ / creativecommons.org/licenses/by/4.0/). 